\title{
Integrative medicine and surgery: what are the diet and supplement recommendations for someone with pancreatic cancer?
}

\author{
Andrew A. Gumbs ${ }^{1,2}$, Gaya Spolverato ${ }^{3}$, Elie Chouillard ${ }^{1}$ \\ ${ }^{1}$ Département de Chirurgie Digestive, Centre Hospitalier Intercommunal de Poissy/Saint-Germain-en-Laye, Poissy, France; ${ }^{2}$ Grigol Robakidze \\ University School of Medicine, T'bilisi, Republic of Georgia; ${ }^{3}$ Department of Surgical, Oncological and Gastroenterological Sciences, Hospital of \\ the University of Padova, Padova, Italy \\ Correspondence to: Andrew A. Gumbs, MD, FACS. Département de Chirurgie Viscérale et Digestive, Centre Hospitalier de Poissy/Saint-Germain, 10 \\ rue du Champ Gaillard, 78300 Poissy, France. Email: aagumbs@gmail.com.
}

Submitted Dec 30, 2020. Accepted for publication Mar 11, 2021.

doi: $10.21037 / \mathrm{hbsn}-20-863$

View this article at: https://dx.doi.org/10.21037/hbsn-20-863

Although a study in 2009 analyzing 20,000 cancer patients argued for a protective effect against pancreatic cancer in patients who adhered to a Mediterranean diet, the European Prospective Investigation into Cancer and Nutrition (EPIC) study looked at a population of 10 million people and identified 865 patients with pancreatic cancer and did not find a link to pancreatic cancer risk when a strict Mediterranean diet was followed (1). Regardless, there is a well-known correlation between obesity leading to chronic inflammation and resultant carcinogenesis (2). Decreasing body fat is indisputable in the literature for minimizing both the risk of cancer and the risk of recurrence. Pancreatic cancer is currently within the list of obesity-related cancers, together with colon, esophageal, endometrial, renal and postmenopausal breast cancer (3). A large case-controlled study from the USA associated obesity to a 50-60\% elevated risk of developing pancreatic cancer, which was particularly elevated among African-Americans and women (4). In short, higher body mass index (BMI) is associated with more cancers and increased risk of diabetes, indicating that a normal BMI should be sought and maintained in patients with an increased risk or history of pancreatic cancer.

Although it is tempting to advocate for a vegan diet for patients with pancreatic cancer, the data is not conclusive or realistic for all patients. There is no debate that a vegan diet is certainly better to reduce the rate of global warming and the mass extermination of animals, however, vegan diets are currently expensive, potentially time-consuming for neophytes and difficult to push for in patients that may need major digestive surgery and chemotherapy that is notorious for causing nausea, anorexia and weight loss. Nonetheless, a plant-based diet with minimal consumption of animal protein certainly seems a realistic goal. A casecontrolled study in the above-mentioned EPIC cohort study demonstrated an inverse relationship between plasma levels of beta-carotene (citrus fruits and leafy green vegetables), zeaxantin (corn, paprika and wolfberries) and alpha-tocopherol (green vegetables and tomatoes) and the risk of pancreatic cancer. Furthermore, some isothiocyanates, which are found in cruciferous vegetables such as cauliflower and broccoli, have been found to inhibit pancreatic cancer cells growth in vitro and also in animal studies (5). A vegan diet with vitamin B12 supplementation certainly does not have any down-sides (6).

Regardless, we now recommend an anti-inflammatory diet (AID) for all of our cancer patients, it is essentially a plant-based diet without the strict interdiction of the occasional animal product; and data has recently been published in Nature arguing for an improved prognosis in breast cancer patients (7). As recommended in the AID, a prospective study on 75,680 women who ate a 28 grams of nuts, at least 2 times a week, were found to have a decreased risk of pancreatic cancer (8). This could be due to better glycemic control, decreased ingestion of animal products or something inherent in the nuts (9). Nuts have also long been known to reduce the risk of diabetes mellitus and cardiovascular disease, two factors that have a strong influence on mortality and overall survival. 
Green tea has been long touted as having potential anticancer activity. It is known to contain catechins, which have been shown to have anti-tumor activity. However, the data for pancreatic cancer in particular is inconclusive, with some papers arguing for its consumption and others arguing against it (10). Regardless, the potential to reduce the risk of cancers as a whole seems worthwhile for any patient. At least 5 cups of organic green tea are recommended for a protective effect. Caffeine can be removed by dipping the tea in boiling water for 30 seconds prior to steeping. Gyokuro tea is generally believed to be the best type of green tea for stress reduction and, therefore, anti-tumor effects.

The supplements we recommend for prevention of pancreatic cancer and recurrence include vitamin D3, fish oil, curcumin, melatonin, Asian mushrooms and probiotics. A vitamin D3 level less than $30 \mathrm{ng} / \mathrm{mL}$ is deficient. Vitamin $\mathrm{D}$ deficiency is associated with increased risk of pancreatic cancer. Vitamin D decreases proliferation of cancer cells and decreases growth in vitro it is also believed that it helps inhibit pancreatic cancer invasion and metastasis (11). We recommend that our patients take enough vitamin D3 to keep their levels between 50 and $100 \mathrm{ng} / \mathrm{mL}$, but no higher than this as high vitamin $\mathrm{D}$ levels may contribute to carcinogenesis (11).

Studies are emerging that report that supplementation with fish oil may reduce the risk of developing certain cancers, including pancreatic cancer. Observations such as these make it difficult to demand a strict vegan diet from my patients. We ask them to take at least 2,000 mg of EPA + DHA daily. This is the equivalent of 7 fish oil capsules, or 4 capsules of omega-3 supplements that are concentrated. Patients are asked to be sure to look at the back of the bottle and add up how much is in each capsule.

Curcumin is believed to have anti-inflammatory properties and believed to potentially explain the relatively low incidence of colon cancer in populations such as India that ingest large amounts of curcumin (12). Turmeric has been shown to be potentially advantageous in pancreatic cancer cell lines treated with gemcitabine-based chemotherapy (13). It is, therefore, tempting to consider curcumin and cannabidiol (CBD) oil in patients with pancreatic cancer undergoing chemotherapeutic treatments with gemcitabine. If curcumin is prescribed, we recommend $600 \mathrm{mg}$ twice a day, with bioperine, or black pepper as it helps with absorption into the blood stream.

Interestingly, curcumin has also been theorized to influence the microbiome in a manner that inhibits colon cancer proliferation. There has been an explosion of interest in the potential for probiotics to decrease the risk of developing cancers in general and digestive cancers in particular. It seems reasonable to assume that patients would pancreatic cancer might benefit from a regulated microbiome through the use of certain probiotics (14).

In experimental models certain extracts of Asian mushrooms from traditional Chinese medicine have shown anti-tumor activity in pancreatic cancer cell lines. Mushroom extracts from an international study showed tumor suppression in an experimental model published in 2013 (15). Although these mushrooms should probably be obtained through a licensed Chinese Medical Doctor, regulations are different depending on the State regulatory body. Although we do not routinely prescribe these, if we have a patient who is already on them, we will do not ask them to stop taking them.

Innumerable studies have indicated that melatonin supplementation may have a protective effect against carcinogenesis and may even induce apoptosis (16). We recommend $20 \mathrm{mg}$ to be taken by mouth 1 hour before bedtime for my cancer patients, counter intuitively, lower doses are actually more effective for patients with insomnia. We also believe THC heavy marijuana is particularly useful for patients with cancer and insomnia, and the fact that all marijuana also has some CBD seems potentially doubly beneficial.

\section{Acknowledgments}

Funding: Grigol Robakidze University School of Medicine, T'bilisi, Republic of Georgia.

\section{Footnote}

Provenance and Peer Review: This article was a standard submission to the journal Hepatobiliary Surgery and Nutrition. The article did not undergo external peer review.

Conflicts of Interest: All authors have completed the ICMJE uniform disclosure form (available at https://hbsn. amegroups.com/article/view/10.21037/hbsn-20-863/coif). The authors have no conflicts of interest to declare.

Ethical Statement: The authors are accountable for all aspects of the work in ensuring that questions related to the accuracy or integrity of any part of the work are appropriately investigated and resolved. Written informed consent was obtained from the patient for publication of 
this manuscript and any accompanying images.

Open Access Statement: This is an Open Access article distributed in accordance with the Creative Commons Attribution-NonCommercial-NoDerivs 4.0 International License (CC BY-NC-ND 4.0), which permits the noncommercial replication and distribution of the article with the strict proviso that no changes or edits are made and the original work is properly cited (including links to both the formal publication through the relevant DOI and the license). See: https://creativecommons.org/licenses/by-nc-nd/4.0/.

\section{References}

1. Molina-Montes E, Sánchez MJ, Buckland G, et al. Mediterranean diet and risk of pancreatic cancer in the European Prospective Investigation into Cancer and Nutrition cohort. Br J Cancer 2017;116:811-20.

2. Gumbs AA. Obesity, pancreatitis, and pancreatic cancer. Obes Surg 2008;18:1183-7.

3. Azvolinsky A. Cancer risk: the fat tissue-BMI-obesity connection. J Natl Cancer Inst 2014;106:dju100.

4. Silverman DT, Swanson CA, Gridley G, et al. Dietary and nutritional factors and pancreatic cancer: a case-control study based on direct interviews. J Natl Cancer Inst 1998;90:1710-9.

5. Jeurnink SM, Ros MM, Leenders M, et al. Plasma carotenoids, vitamin $\mathrm{C}$, retinol and tocopherols levels and pancreatic cancer risk within the European Prospective Investigation into Cancer and Nutrition: a nested casecontrol study: plasma micronutrients and pancreatic cancer risk. Int J Cancer 2015;136:E665-76.

6. Selinger E, Kühn T, Procházková M, et al. Vitamin B12 Deficiency Is Prevalent Among Czech Vegans Who Do Not Use Vitamin B12 Supplements. Nutrients 2019;11:3019.

Cite this article as: Gumbs AA, Spolverato G, Chouillard E. Integrative medicine and surgery: what are the diet and supplement recommendations for someone with pancreatic cancer? HepatoBiliary Surg Nutr 2021;10(5):741-743. doi: $10.21037 / \mathrm{hbsn}-20-863$
7. Wang K, Sun JZ, Wu QX, et al. Long-term antiinflammatory diet in relation to improved breast cancer prognosis: a prospective cohort study. NPJ Breast Cancer 2020;6:36.

8. Bao Y, Han J, Hu FB, et al. Association of nut consumption with total and cause-specific mortality. N Engl J Med 2013;369:2001-11.

9. Bao Y, Hu FB, Giovannucci EL, et al. Nut consumption and risk of pancreatic cancer in women. Br J Cancer 2013;109:2911-6.

10. Bimonte S, Cascella M, Leongito M, et al. An overview of pre-clinical studies on the effects of (-)-epigallocatechin3 -gallate, a catechin found in green tea, in treatment of pancreatic cancer. Recenti Prog Med 2017;108:282-7.

11. Bulathsinghala P, Syrigos KN, Saif MW. Role of vitamin $\mathrm{d}$ in the prevention of pancreatic cancer. J Nutr Metab 2010;2010:721365.

12. McFadden RM, Larmonier CB, Shehab KW, et al. The Role of Curcumin in Modulating Colonic Microbiota During Colitis and Colon Cancer Prevention. Inflamm Bowel Dis 2015;21:2483-94.

13. Yoshida K, Toden S, Ravindranathan P, et al. Curcumin sensitizes pancreatic cancer cells to gemcitabine by attenuating PRC2 subunit EZH2, and the lncRNA PVT1 expression. Carcinogenesis 2017;38:1036-46.

14. Singhal B, Mukherjee A, Srivastav S. Role of Probiotics in Pancreatic Cancer Prevention: The Prospects and Challenges. Adv Biosci Biotechnol 2016;7:468-500.

15. Cheng S, Eliaz I, Lin J, et al. Triterpenes from Poria cocos suppress growth and invasiveness of pancreatic cancer cells through the downregulation of MMP-7. Int J Oncol 2013;42:1869-74. Erratum in: Int J Oncol 2014;44:1781.

16. Tamtaji OR, Mirhosseini N, Reiter RJ, et al. Melatonin and pancreatic cancer: Current knowledge and future perspectives. J Cell Physiol 2019;234:5372-8. 